\title{
$\alpha$ NAC depletion as an initiator of ER stress-induced apoptosis in hypoxia
}

\author{
Y Hotokezaka ${ }^{1}$, K van Leyen ${ }^{2}$, EH Lo ${ }^{2}$, B Beatrix ${ }^{3}$ I Katayama ${ }^{1}$, G Jin² and T Nakamura ${ }^{\star, 1}$
}

Accumulation of unfolded proteins triggers endoplasmic reticulum (ER) stress and is considered a part of the cellular responses to hypoxia. The nascent polypeptide-associated complex (NAC) participates in the proper maturation of newly synthesized proteins. However, thus far, there have been no comprehensive studies on NAC involvement in hypoxic stress. Here, we show that hypoxia activates glycogen synthase kinase-3 $\beta$ (GSK-3 $\beta$ ) and that the activated GSK-3 $\beta$ destabilizes $\alpha$ NAC with the subsequent apoptosis of the cell. Hypoxia of various cell types and the mouse ischemic brain was associated with rapid downregulation of $\alpha$ NAC and ER stress responses involving PERK, ATF4, $\gamma$-taxilin, elF2 $\alpha$, Bip, and CHOP. Depletion of $\alpha$ NAC by RNA interference specifically activated ER stress responses and caused mitochondrial dysfunction, which resulted in apoptosis through caspase activation. Interestingly, we found that the hypoxic conditions activated GSK-3 $\beta$, and that GSK-3 $\beta$ inhibition prevented $\alpha$ NAC protein downregulation in hypoxic cells and rescued the cells from apoptosis. In addition, $\alpha$ NAC overexpression increased the viability of hypoxic cells. Taken together, these results suggest that $\alpha$ NAC degradation triggers ER stress responses and initiates apoptotic processes in hypoxic cells, and that GSK-3 $\beta$ may participate upstream in this mechanism.

Cell Death and Differentiation (2009) 16, 1505-1514; doi:10.1038/cdd.2009.90; published online 17 July 2009

The endoplasmic reticulum (ER) is the principal organelle that ensures correct control of protein folding and assembly. The perturbations that alter ER homeostasis can lead to the accumulation of unfolded proteins (UPs). To cope with this stress, cells activate an intracellular signaling pathway, the unfolded protein response (UPR). The UPR transmits information on the status of protein folding in the ER lumen to the cytoplasm and nucleus. ${ }^{1}$ Cells that fail to restore a proper ER homeostasis are eventually eliminated by ER stress-induced, programed cell death. ${ }^{2}$

Eukaryotic cells also use sophisticated mechanism to ensure the proper folding and targeting of newly synthesized proteins. The nascent polypeptide-associated complex (NAC) is the first non-ribosomal protein that the growing nascent chains (NCs) encounter. In addition to protecting the growing NCs on the ribosome from premature encounters, the NAC may also contribute to the inhibition of ribosomal binding to the ER membrane, and cotranslational protein import into the mitochondria. ${ }^{3,4}$

The cellular function of NAC appears to be diverse, and it is not restricted to translation. Prolonged ER stress is linked to the pathogenesis of several different neurodegenerative disorders. For example, the intracellular levels of the NAC subunits change dramatically in several human diseases such as Alzheimer's disease (AD) and malignant brain tumors., ER stress has also been observed following cerebral ischemia and reperfusion. Recently, $\beta$ NAC was found to be a critical determinant of developmentally programed cell death of C. elegans. ${ }^{7}$ Several publications have implicated the role of the NAC complex in apoptosis, but there is little information as to the pathways involved. The physiological significance of the cellular function of NAC has been determined in several studies using yeast, Drosophila, and mice..$^{8-10}$

Perturbation of ER functions with the resultant induction of ER stress responses may occur under various conditions such as hypoxia. ${ }^{11}$ UPR is activated in tumor cells that are propagated in a poorly vascularized environment. Tumor cells are susceptible to nutrient starvation and hypoxic conditions that are prevalent in such an environment. However, tumor cells that survive the hypoxic conditions (hypoxic cells) confer radiotherapy and chemotherapy resistance, and also contribute to the selection of a more malignant phenotype, such as a metastatic phenotype. ${ }^{12,13}$ Therefore, resistance to hypoxia is a crucial factor for determining solid tumor progression and treatment efficacy. However, the involvement of $\alpha$ NAC in hypoxia-induced ER stress responses still remains to be explored.

In this study, we show that hypoxia downregulates $\alpha$ NAC but not $\beta N A C$. We found that $\alpha$ NAC downregulation in hypoxic cells or $\alpha$ NAC ablation by $\alpha$ NAC short-interfering RNA (siRNA) leads to the initiation of ER stress responses, which results in caspase-dependent apoptosis. Maintaining $\alpha$ NAC protein levels by inhibiting glycogen synthase kinase-3 $\beta$ (GSK-3 $\beta$ ) or overexpression of $\alpha \mathrm{NAC}$ reversed these effects in hypoxic

\footnotetext{
${ }^{1}$ Department of Radiology and Cancer Biology, Nagasaki University School of Dentistry, 1-7-1 Sakamoto, Nagasaki 852-8588, Japan; ${ }^{2}$ Neuroprotection Research Laboratory, Departments of Radiology and Neurology, Massachusetts General Hospital and Harvard Medical School, Charlestown, MA 02129, USA and ${ }^{3}$ Gene Center, Department of Chemistry and Biochemistry, University of Munich, LMU, Feodor-Lynen Street 25, Munich 81377, Germany

*Corresponding author: T Nakamura, Department of Radiology and Cancer Biology, Nagasaki University School of Dentistry, 1-7-1 Sakamoto, Nagasaki 852-8588, Japan. Tel: + 8195819 7707; Fax: + 8195819 7711; E-mail: taku@nagasaki-u.ac.jp

Keywords: nascent polypeptide-associated complex; apoptosis; ER stress; glycogen synthase kinase; hypoxia

Abbreviations: NAC, nascent polypeptide-associated complex; ER, endoplasmic reticulum; UPs, unfolded proteins; UPR, unfolded protein response; NCs, growing nascent chains; $A D$, Alzheimer's disease

Received 18.9.08; revised 02.6.09; accepted 09.6.09; Edited by SH Kaufmann; published online 17.7.09
} 
cells. These results suggest that $\alpha \mathrm{NAC}$ downregulation is a key initiator of hypoxia-induced apoptosis.

\section{Results}

Hypoxia induces $\alpha$ NAC downregulation. To test the possible involvement of $\alpha$ NAC in hypoxia-induced apoptosis, we examined whether the hypoxic condition could affect the levels of $\alpha$ NAC protein expression in HeLa S3 cells (Figure 1a-e). HeLa S3 cells cultured under hypoxic conditions exhibited gradual decreases in the $\alpha$ NAC protein levels, which was evident at $4 \mathrm{~h}$ after the hypoxic treatment and reached levels less than $20 \%$ of the controls by $24 \mathrm{~h}$. Annexin-positive apoptotic cells were not observed within
$16 \mathrm{~h}$ after the treatment, indicating that the $\alpha \mathrm{NAC}$ downregulation preceded the appearance of apoptotic phenotype (Figure 1c and d). Importantly, hypoxia-induced aNAC downregulation is caspase-independent (Figure 1e).

Hypoxia-induced $\alpha$ NAC downregulation was also observed in other cell types such as SH-SY5Y neuroblastoma cells (Figure 1f-i). The apoptotic changes were evident $16 \mathrm{~h}$ after the initiation of cell culture under hypoxic conditions. The hypoxia-induced $\alpha$ NAC downregulation preceded ( $8 \mathrm{~h}$ after the initiation of hypoxic stress) the appearance of the apoptotic phenotype. In contrast, $\beta$ NAC $\left(\beta_{1}\right.$ NAC and $\beta_{2} N A C$ ) expression was not significantly affected by hypoxia (Figure 1f). These results are consistent with the notion that the integrity of $\beta \mathrm{NAC}$ is not dependent on the presence of $\alpha \mathrm{NAC}^{10}$

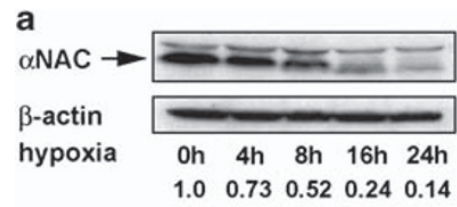

b
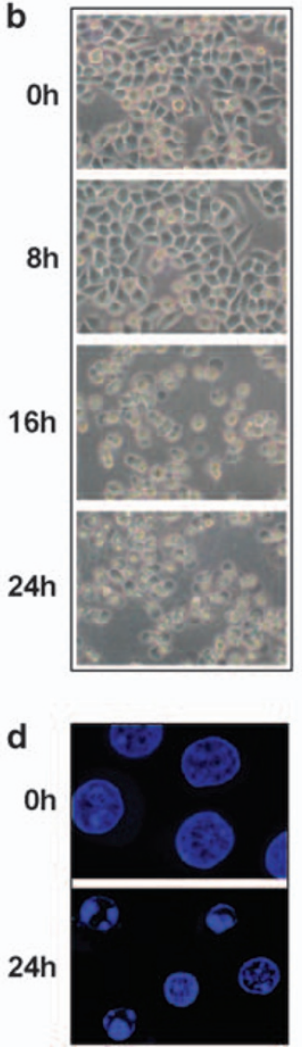

c
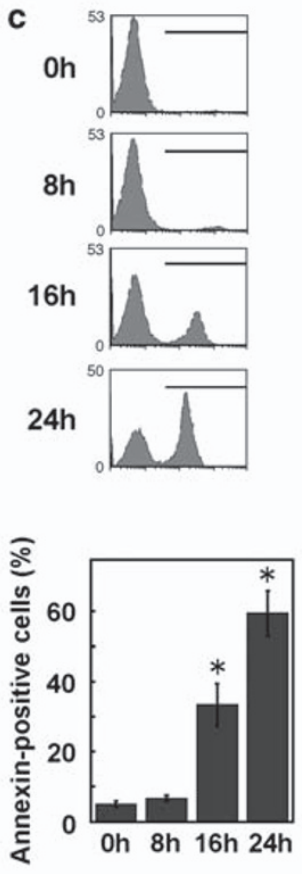

e

$\alpha$ NAC

Cleaved

Caspase-9

$\beta$-actin

hypoxia

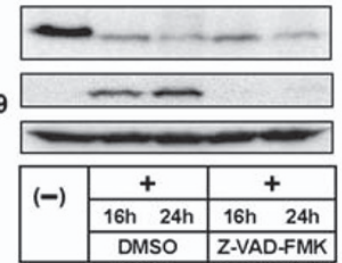

f

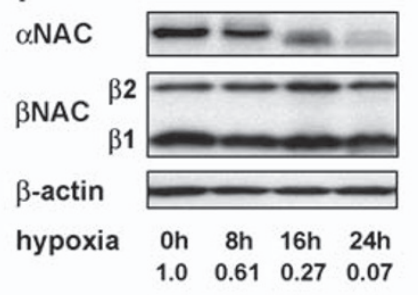

g

Oh

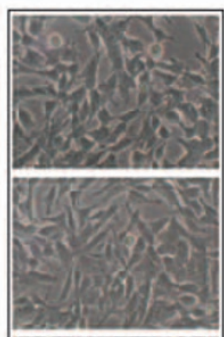

$16 \mathrm{~h}$

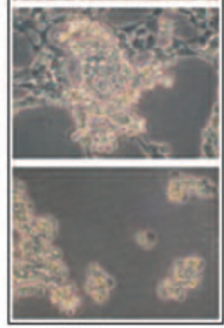

h

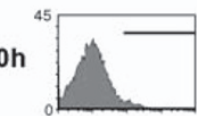

$8 \mathrm{~h}$
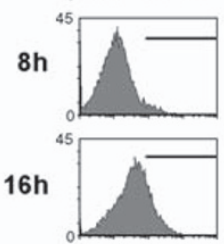

$24 \mathrm{~h}$

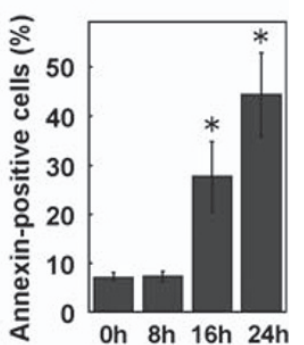

i

$\mathrm{Oh}$

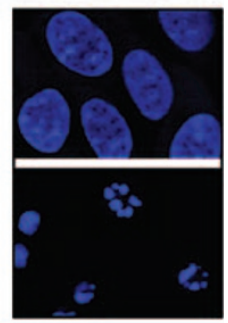

Figure 1 Downregulation of $\alpha$ NAC in hypoxia. (a) Downregulation of $\alpha$ NAC in hypoxic HeLa S3 cells. Western blot analysis was performed 0-24h after hypoxic treatment of cells. Blots were quantified using a densitometer and $\alpha \mathrm{NAC}$ levels normalized to the corresponding actin levels; results are shown below the hypoxic durations and expressed relative to control $(0 \mathrm{~h})$. (b) Phase-contrast micrographs show floating cells observed $16 \mathrm{~h}$ after the beginning of hypoxic treatment. (c) FACS analysis of apoptosis in hypoxic HeLa S3 cells (upper panel). Bar graph indicates the relative numbers of annexin-positive cells (lower panel). Bars in the FACS profiles (upper panel) indicate the fractions of annexin-positive cells. Bar graph data are shown as means \pm S.D. $(n=3)$. *Differences are significant $(P<0.01)$ versus controls $(0 \mathrm{~h})$. (d) DAPI staining shows fragmented nuclei of apoptotic HeLa S3 cells after hypoxic treatment. (e) Hypoxia-induced $\alpha$ NAC downregulation is caspase-independent. HeLa S3 cells were cultured on the hypoxic conditions for 16 or $24 \mathrm{~h}$ in the presence or absence of $100 \mu \mathrm{m}$ Z-VAD-FMK. Blots for cleaved caspase-9 were used as controls demonstrating that Z-VAD-FMK effectively inhibited the caspase activity (also see Figure 5e). (f) Downregulation of $\alpha$ NAC in hypoxic SH-SY5Y neuroblastoma cells. Note that $\beta_{1}$ and $\beta_{2}$ indicate the splicing variants of $\beta$ NAC. (g) Phase-contrast micrographs show floating cells observed $16 \mathrm{~h}$ after the beginning of hypoxic treatment. (h) FACS analysis of apoptosis in hypoxic SHSY5Y cells. Bar graph data are shown as means \pm S.D. $(n=3)$. ${ }^{*}$ Differences are significant $(P<0.01)$ versus controls $(0 \mathrm{~h})$. (i) DAPI staining of apoptotic SH-SY5Y cells after hypoxic treatment 

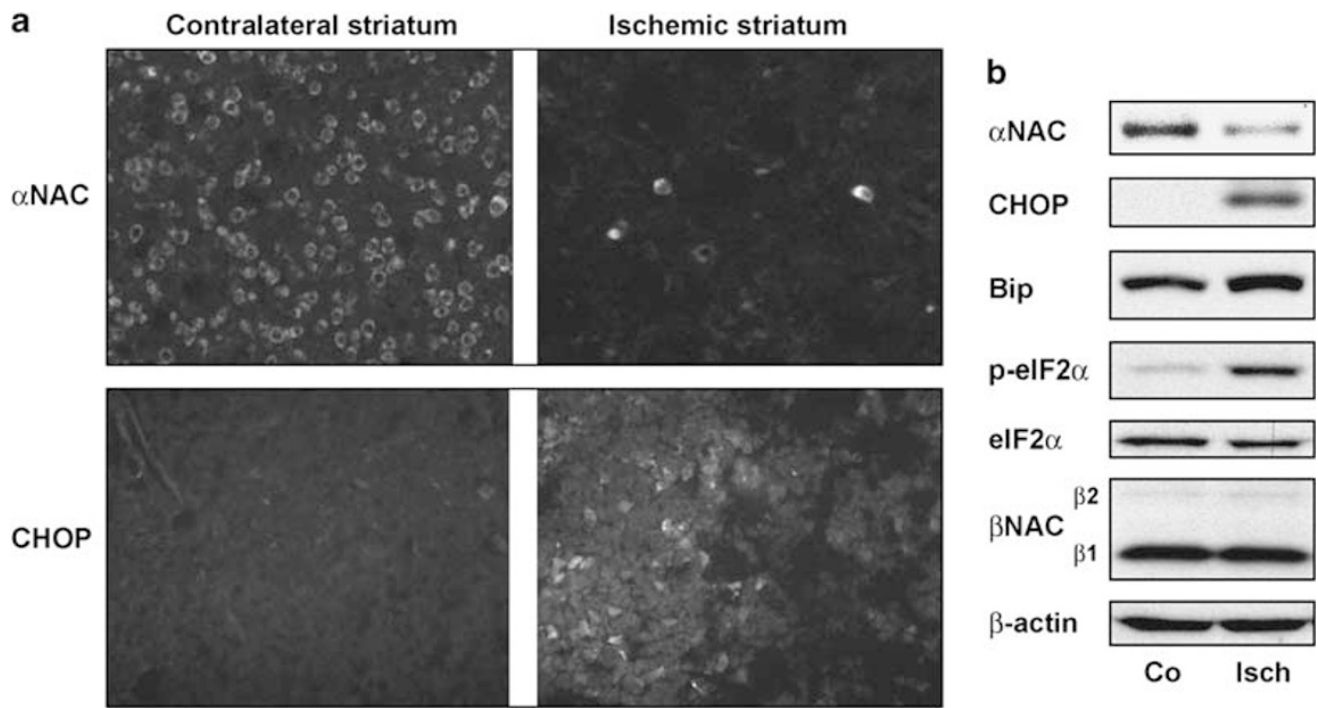

Figure $2 \alpha$ NAC downregulation in mouse ischemic brain. (a) Immunohistochemical photomicrographs show $\alpha$ NAC depletion (upper panels) and CHOP induction (lower panels) in the mouse striatum that had undergone transient focal cerebral ischemia/reperfusion. (b) Western blot analysis of homogenates from ischemic (Isch) and contralateral (Co) hemispheres. Note that ischemia significantly decreased but not completely suppressed the $\alpha$ NAC signals. Also note that $\beta$ NAC remains unaffected by brain ischemia

The hypoxic state also occurs in brain ischemia. Therefore, we examined mouse brains after temporary $(2 \mathrm{~h})$ occlusion of the right middle cerebral artery. ${ }^{14}$ We assessed the ischemic mouse brain $22 \mathrm{~h}$ after the reperfusion. In the contralateral non-ischemic brains, $\alpha$ NAC was expressed in almost all the neurons (Figure 2). However, except for strong staining in some neuronal cells, $\alpha$ NAC expression was barely detected in the ischemic side of the striatum. Western blot analysis using homogenates obtained separately from the ischemic and contralateral hemispheres showed that $\alpha$ NAC expression was greatly decreased in the ischemic hemisphere; the incomplete suppression in $\alpha \mathrm{NAC}$ expression may be because of the use of homogenates from the whole ischemic hemisphere, which comprises not just heavily damaged regions such as the striatum, but also the less damaged cortex, in which $\alpha$ NAC staining persists at this time point (Figure 2b). Therefore, these results suggest that $\alpha$ NAC depletion is not solely a response in hypoxic HeLa S3 cells. As in the case of the hypoxic $\mathrm{SH}-\mathrm{SY} 5 \mathrm{Y}$ cells, $\beta$ NAC expression was not affected by the ischemic assault (Figure $2 b$ ).

aNAC downregulation is sufficient for the induction of apoptosis. Next, we asked whether $\alpha$ NAC downregulation is sufficient to trigger apoptosis in cells cultured under nonhypoxic conditions. To this end, we depleted $\alpha$ NAC by RNA interference (Figure $3 a-e)$. The $\alpha$ NAC ablation by specific siRNA caused apoptosis as evident by Annexin (Figure 3d) and Tunel (Figure $3 e$ ) assays. The appearance of apoptotic nuclear phenotype was restricted to the cells with decreased $\alpha$ NAC protein, suggesting the specificity of the apoptotic effects exerted by $\alpha$ NAC depletion (Figure 3c). A different $\alpha$ NAC siRNA oligonucleotide with a lower inhibitory effect on aNAC expression displayed proportionally lower apoptosisinducing activity, indicating a dose-response relationship between $\alpha$ NAC downregulation and the apoptotic phenotype (Supplementary Figure S1).

aNAC depletion initiates ER stress. Endoplasmic reticulum dysfunction has been postulated as a common pathologic denominator underlying acute and chronic neurodegenerative disorders, including brain ischemia. ${ }^{15,16}$ Therefore, we wished to test the hypothesis that $\alpha \mathrm{NAC}$ depletion might lead to the activation of the UPR in the ER.

Endoplasmic reticulum stress signaling pathways involve three distinct stress sensor proteins (PERK, IRE1, and ATF6). ${ }^{17}$ Bip is the master regulator of these three sensor proteins. Therefore, we first monitored the expression levels of Bip in $\alpha$ NAC-depleted HeLa S3 cells. We found that the Bip levels were elevated $72 \mathrm{~h}$ after the initiation of the siRNA treatment (Figure 4a). The dissociation of Bip from PERK leads to autophosphorylation of PERK, which in return phosphorylates elF2 $\alpha$ and then activates ATF4 translation. ATF4 increases the expression of proapoptotic factor $\mathrm{CHOP}$. We found that $\alpha$ NAC ablation by RNA interference activated the phosphorylation of PERK and elF2 $\alpha$ in HeLa S3 cells (Figure $4 \mathrm{a}$ ). These changes were first evident at $48 \mathrm{~h}$ after the initial addition of the siRNA and persisted at least in the following $24 \mathrm{~h}$. On the other hand, the upregulation of $\mathrm{CHOP}$ expression was transient and the expression levels returned to those of the controls $72 \mathrm{~h}$ after the initial addition of the siRNA. $\alpha$ NAC ablation by siRNA interference did not significantly affect the $\beta N A C$ protein levels (Figure 4a). Similar changes were observed in the mouse ischemic brain (Figure 2) and in the hypoxic SK-N-SH cells (Supplementary Figure S2).

We also found that in the $\alpha$ NAC-depleted cells, ATF4 protein levels were slightly increased. Previous reports have shown that $\gamma$-taxilin is a regulator of ATF 4 activity and interacts with $\alpha$ NAC. ${ }^{18,19}$ Therefore, we assessed $\gamma$-taxilin protein 


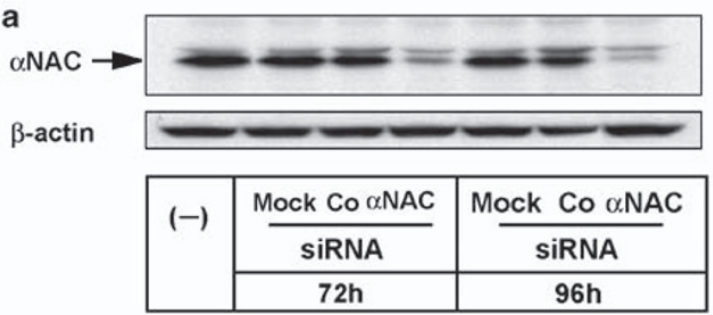

b

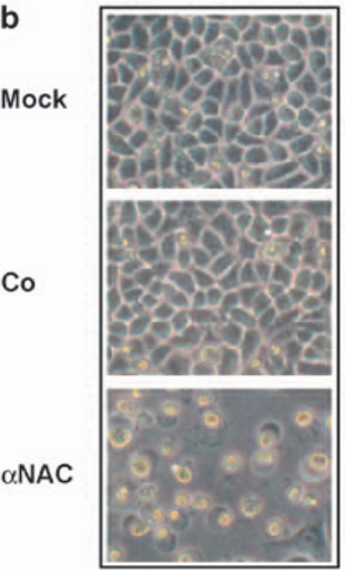

C

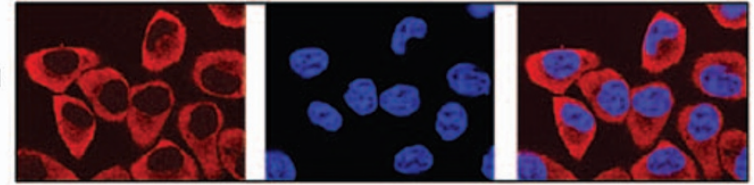

Control SiRNA

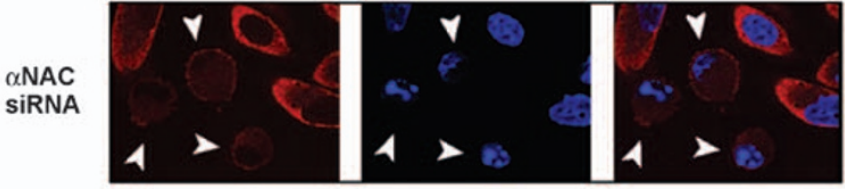

$\alpha$ NAC

DAPI

Merge

e

d
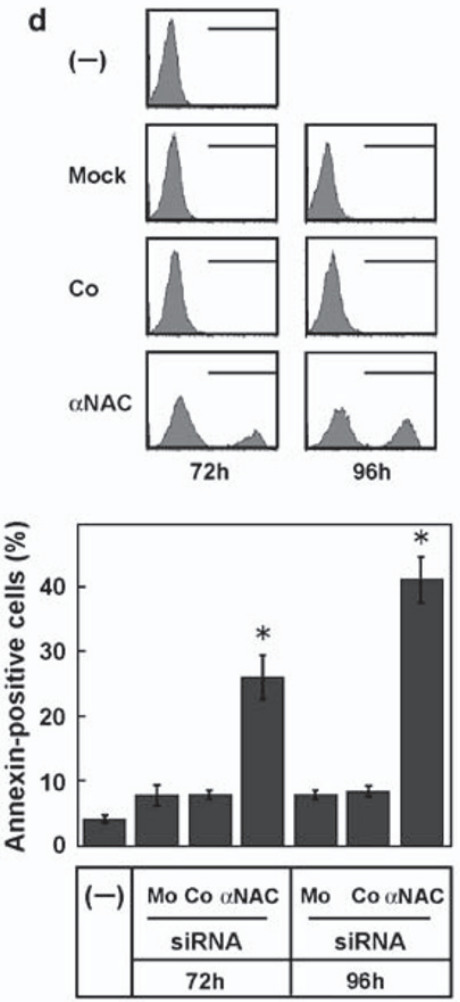
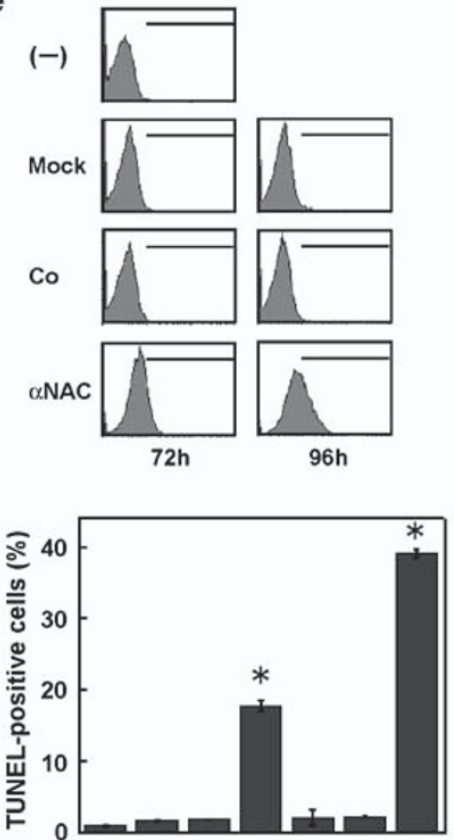

\begin{tabular}{|c|c|c|}
\hline$(-)$ & $\frac{\text { Mo Co } \alpha \text { NAC }}{\text { siRNA }}$ & $\frac{\text { Mo Co } \alpha \text { NAC }}{\text { siRNA }}$ \\
\cline { 2 - 3 } & $72 \mathrm{~h}$ & $96 \mathrm{~h}$ \\
\hline
\end{tabular}

Figure 3 Ablation of $\alpha$ NAC induces apoptosis. (a) Inhibition of $\alpha$ NAC expression by siRNA induces apoptosis in HeLa S3 cells. The HeLa S3 cells were not treated (-), treated with solvent alone (Mock), treated with control siRNA (Co), or treated with $\alpha$ NAC siRNA ( $\alpha$ NAC), for 72 or $96 \mathrm{~h}$. (b) Phase-contrast micrographs show HeLa S3 cells $96 \mathrm{~h}$ after mock-treatment (Mock), RNA interference with control siRNA (Co), or $\alpha$ NAC siRNA ( $\alpha \mathrm{NAC}$ ). (c) Confocal microscopy demonstrates the correlation of $\alpha$ NAC depletion and apoptotic changes in HeLa S3 cells treated with control or $\alpha$ NAC siRNA. Arrows indicate fragmented apoptotic nuclei in HeLa S3 cells with depleted $\alpha$ NAC. (d and e) Induction of apoptosis by aNAC depletion in HeLa S3 cells. Apoptosis was assessed by annexin (d) or TUNEL (e) assay. aNAC depletion caused apoptosis in HeLa S3 cells, but mock-treatment (Mock) or control (Co) siRNA treatment did not. Bar graph data are shown as means \pm S.D. $(n=3)$. ${ }^{*}$ Differences are significant $(P<0.01)$ versus mock-treated cells (Mo)

levels in $\alpha$ NAC-depleted cells, and found that $\gamma$-taxilin was downregulated in $\alpha$ NAC siRNA-treated cells (Figure 4a) and hypoxic cells (Supplementary Figure S2).

The dissociation of Bip from IRE1 permits the homodimerization and activation of IRE1. The activated IRE1 serves a proapoptotic function by inducing the activation of C-Jun $\mathrm{N}$-terminal kinase (JNK). ${ }^{20}$ On the other hand, the dissociation of Bip from ATF6 permits the translocation of ATF6 into the Golgi compartment for intramembrane proteolysis. However, we did not observe significant changes in the levels of phosphorylated $\mathrm{JNK}^{21}$ or any product of the spliced XBP1 mRNA ${ }^{22}$ (Supplementary Figure S3). In addition, the expression of cleaved ATF6 was not observed in HeLa
S3 cells. Taken together, these results suggest that the aNAC depletion-induced ER stress response occurred chiefly, if not exclusively, through the PERK-elF2 $\alpha$ sensor pathway.

Ubiquitin accumulation in aNAC-depleted cells. Unfolded or misfolded proteins that are not transported from the ER to the Golgi compartment may be degraded by the ubiquitin/ proteasome pathway. ${ }^{15}$ If this phenomenon occurs in $\alpha$ NACdepleted cells, ubiquitin must accumulate in the cytoplasm to degrade the unfolded or misfolded proteins. ${ }^{23}$ Therefore, we tested this possibility by the immunohistochemical detection of ubiquitin localization in $\alpha$ NAC-depleted cells. Ubiquitin was 
a

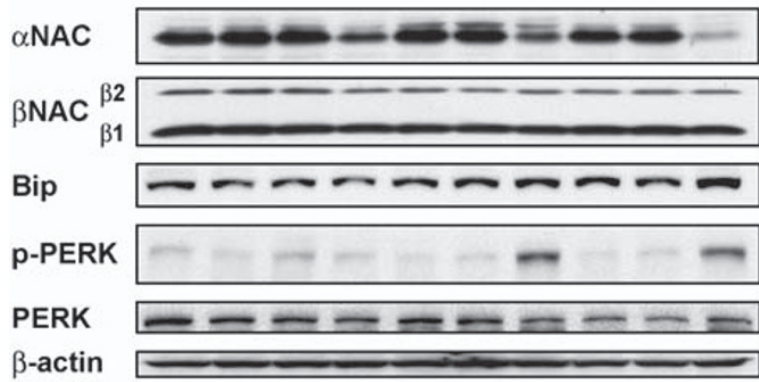

\begin{tabular}{|c|c|c|c|}
\hline \multirow{2}{*}{$(-)$} & $\frac{\text { Mock Co } \alpha \text { NAC }}{\text { siRNA }}$ & $\frac{\text { Mock Co } \alpha N A C}{\text { siRNA }}$ & $\frac{\text { Mock Co } \alpha N A C}{\text { siRNA }}$ \\
\cline { 2 - 4 } & $24 \mathrm{~h}$ & $48 \mathrm{~h}$ & $72 \mathrm{~h}$ \\
\hline
\end{tabular}

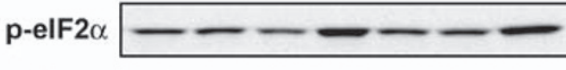

elF2 $\alpha \longrightarrow$

ATF4

$\gamma$-taxilin $=2 \mathrm{man}$

CHOP

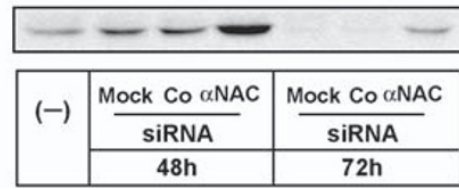

b

\section{Control siRNA}

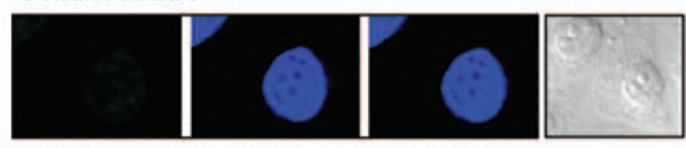

Ubiquitin

DAPI

Merge

aNAC siRNA

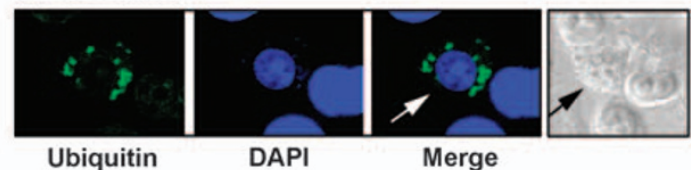

Ubiquitin

DAPI

Merge

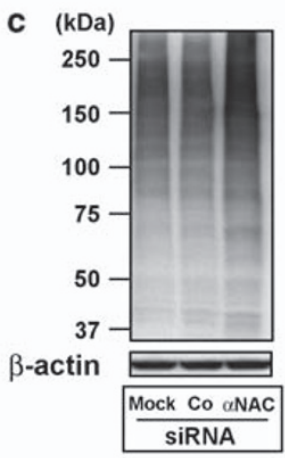

Figure $4 \alpha$ NAC depletion initiates ER stress responses. (a) $\alpha$ NAC ablation by RNA interference induces upregulation of ER stress response proteins in HeLa S3 cells. Western blot analysis was performed before RNA interference (-), or 24, 48, or $72 \mathrm{~h}$ after the addition of solvent alone (Mock), control siRNA (Co), or $\alpha$ NAC siRNA ( $\alpha$ NAC). Note that the $\beta$ NAC level is not affected upon $\alpha$ NAC depletion by RNA interference. (b) Confocal microscopy shows ubiquitin accumulation in the cytoplasm of $\alpha$ NAC-depleted HeLa S3 cells. Arrows on merged confocal images and phase-contrast micrographs indicate cells with apoptotic nuclear morphology. (c) $\alpha$ NAC ablation induces accumulation of ubiquitinated proteins in HeLa S3 cells. Cell lysates were analyzed on $7.5 \%$ SDS-PAGE, followed by immunoblotting with antibodies specific for anti-mono- and polyubiquitinated conjugates (top panel) and $\beta$-actin (bottom panel)

detected in the cytoplasm of apoptotic cells after $\alpha \mathrm{NAC}$ depletion by RNA interference, but not in the cells transfected with the control siRNA (Figure 4b). Western blot analysis demonstrated increases in ubiquitinated proteins in the $\alpha$ NAC-depleted cells (Figure 4c). Collectively, these results suggest that $\alpha \mathrm{NAC}$ depletion induces ER stress responses.

aNAC depletion activates the mitochondrial apoptotic pathway. Endoplasmic reticulum stress with resultant ER dysfunction may initiate an apoptotic pathway involving cytochrome $c$ release from the mitochondria. ${ }^{16}$ In the control siRNA-treated cells, cytochrome $c$ displayed punctate distribution throughout the cytoplasm (Figure 5a) and was not detected in the cytoplasmic fraction of the cell lysates (Figure 5b). However, in the $\alpha$ NAC siRNA-treated cells, cytochrome $c$ lost its characteristic punctate staining pattern (Figure 5a), and some amount of cytochrome $c$ shifted from the mitochondrial to the cytoplasmic fraction (Figure 5b).

The apoptotic cross-talk between the ER and the mitochondria requires calcium signaling from the ER to the mitochondria, which is inhibited by $\mathrm{Bcl}-2$ and promoted by Bax. ${ }^{16} \mathrm{Bcl}-2$ is degraded during the process of cell death. ${ }^{24}$ Therefore, our next step involved the assessment of these signaling events. After $\alpha$ NAC depletion, the Bcl-2 protein expression was inhibited (Figure $5 \mathrm{c}$ ). In contrast, the Bax protein expression was increased. Mock treatment or treatment using the control siRNA did not significantly affect the expression of these proteins.

The mitochondrial apoptotic pathway involves the activation of caspase- $9 .{ }^{25}$ The involvement of caspase- 4 and caspase- 12 has been suggested, but their role in ER stress-induced apoptosis in humans remains controversial. ${ }^{26}$ Therefore, to confirm the involvement of the caspase pathway in $\alpha \mathrm{NAC}$ depletion-induced apoptosis, we monitored caspase- 9 activation. We found that caspase- 9 activation was correlated with Bcl-2 downregulation and Bax upregulation in $\alpha$ NACtreated HeLa S3 cells (Figure 5c). Caspase-4 activation was not observed (Supplementary Figure S3). The involvement of caspase family members in $\alpha$ NAC depletion-induced apoptosis was confirmed with the use of the pan-caspase inhibitor Z-VAD-FMK; this inhibitor greatly reduced the number of annexin-positive cells that were treated by the $\alpha$ NAC siRNA (Figure $5 d$ ). These results suggest the possibility that the Bcl-2 downregulation in the $\alpha$ NAC-depleted cells may occur as a result of caspase-dependent degradation of $\mathrm{Bcl}-2$ protein. Indeed, $\mathrm{Bcl}-2$ is a well-known caspase substrate. However, we found that $\alpha$ NAC siRNA-induced $\mathrm{Bcl}-2$ downregulation still occurred in the presence of Z-VAD-FMK, while Z-VAD-FMK effectively inhibited degradation of caspase-9, a well-known caspase substrate (Figure 5e). 


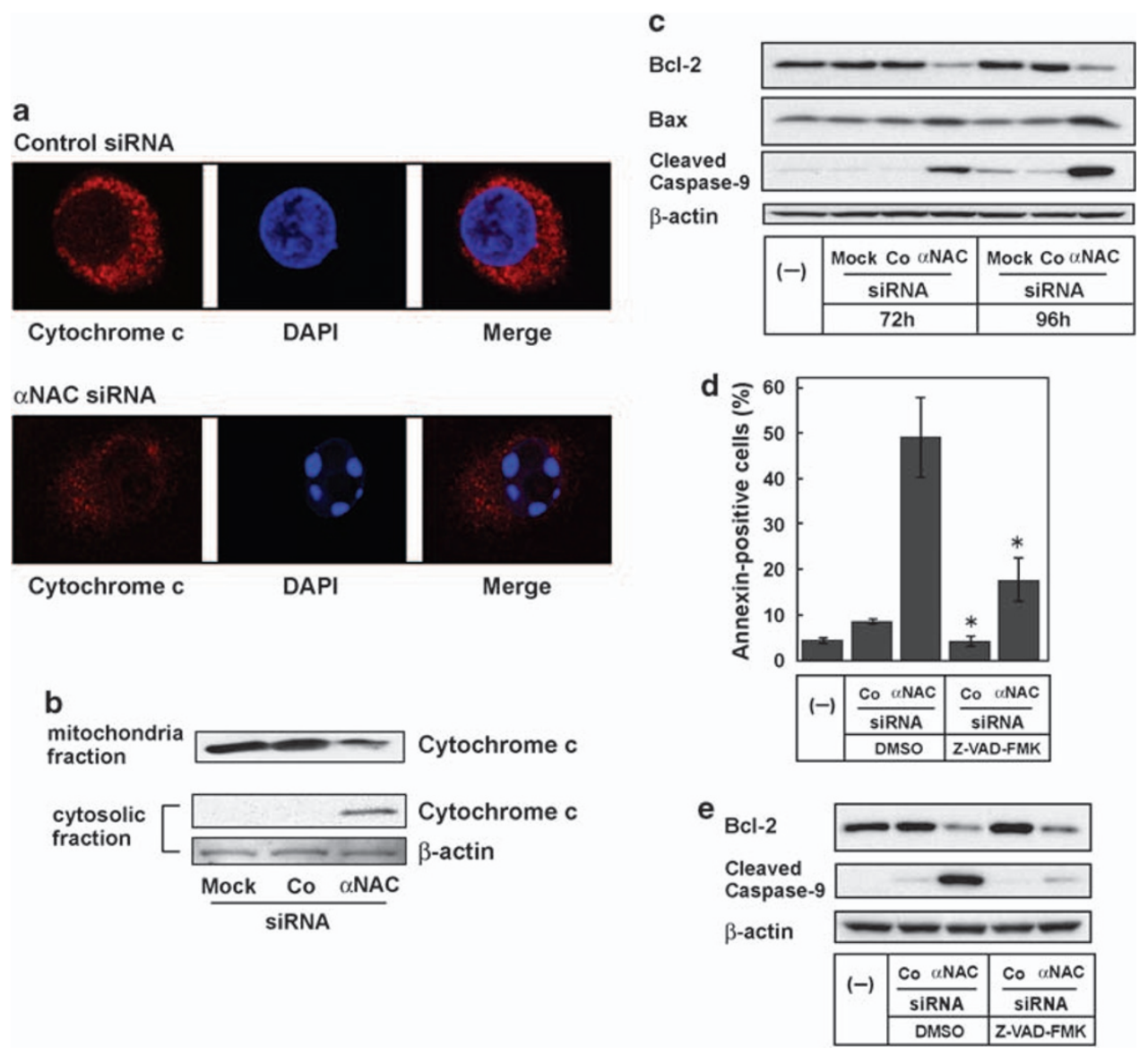

Figure $5 \alpha$ NAC depletion activates apoptotic signal-transduction pathway. (a) Cytochrome $c$ release from mitochondria in $\alpha$ NAC siRNA-treated apoptotic HeLa S3 cells. Cytochrome $c$ loses its speckled cytoplasmic distribution (upper panels) in aNAC siRNA-treated apoptotic cells (lower panels). (b) Cytochrome $c$ is detectable in the cytosolic fractions of $\alpha$ NAC siRNA-treated cells, but not in those from mock-treated (Mock) or control siRNA-treated (Co) cells. (c) Increased expression of death signal proteins (Bax and cleaved caspase-9) and decreased expression of antiapoptotic protein (Bcl-2) in $\alpha$ NAC siRNA-treated HeLa S3 cells. (d) Caspase-dependent cell death in $\alpha$ NAC-depleted HeLa S3 cells. FACS analysis shows that the death of $\alpha$ NAC-depleted cells is caspase-dependent. Bar graph shows the percentage of annexin-positive cells in mock-treated (DMSO) or pancaspase inhibitor-treated (Z-VAD-FMK, $100 \mu \mathrm{M})$ cells. Data are shown as means \pm S.D. $(n=3)$. ${ }^{*}$ Differences are significant $(P<0.01)$ versus corresponding controls (DMSO). (e) $\alpha$ NAC siRNA-induced Bcl-2 downregulation is not caspse-dependent

\begin{abstract}
A steady intracellular level of $\alpha \mathrm{NAC}$ rescues hypoxic cells from apoptosis. These results collectively suggest that $\alpha$ NAC depletion can initiate apoptotic processes in hypoxic cells. Therefore, we hypothesized that if $\alpha$ NAC in hypoxic cells is prevented from degradation, the hypoxic cells could be rescued from apoptosis. GSK- $3 \beta$ is a serine/ threonine protein kinase that regulates a diverse array of cell functions, including signaling by insulin, growth factors, and nutrients, cell fate determination during embryonic development, control of cell division, and microtubule function. ${ }^{27} \mathrm{~A}$ recent study has shown that GSK-3 $\beta$ can phosphorylate $\alpha$ NAC and that the GSK-3 $\beta$-dependent phosphorylation of $\alpha$ NAC stimulated $\alpha$ NAC degradation. ${ }^{28}$ Therefore, we tested the possibility that the prevention of $\alpha$ NAC degradation by the inhibition of GSK-3 $\beta$ might rescue the hypoxic cells from apoptosis. We found that GSK-3 $\beta$ activation and $\alpha$ NAC degradation coincided in hypoxic SK-N$\mathrm{SH}$ cells (Figure 6a). Lithium is a dual inhibitor of GSK-3, reducing the activity directly and also by increasing the inhibitory phosphorylation of GSK-3. ${ }^{29-31}$ Indeed, lithium ions inhibited the dephosphorylation of GSK-3 $\beta$ and, interestingly,
\end{abstract}

concomitantly inhibited the downregulation of aNAC in hypoxic SK-N-SH cells (Figure 6b). More importantly, lithium ions dramatically rescued the hypoxia-induced apoptosis of SK-N-SH cells (Figure 6c-e). The antiapoptotic effects were depended on the lithium ion concentration (Figure 6e). A less effective inhibitor indirubin was proportionally less effective in rescuing the hypoxic cells (Figure $6 \mathrm{~b}$ and d). A third GSK-3 $\beta$ inhibitor, CHIR 99021, which is structurally different from the other two inhibitors, greatly inhibited the downregulation of $\alpha$ NAC in hypoxic cells and improved the viability (Figure $6 b$ and $d$ ). We obtained similar results with HeLa S3 cells (Supplementary Figure S4).

Phosphorylation by p38 MAPK was proposed as an alternative pathway for GSK-3 $\beta$ inactivation. ${ }^{32}$ Arai et al. ${ }^{33}$ demonstrated that ERK signaling pathway is involved in ER stress responses. Therefore, we also tested inhibitors against p38 MAPK and ERK. However, these were ineffective with regard to the recovery of $\alpha \mathrm{NAC}$ from degradation or apoptosis under hypoxic conditions (Supplementary Figure S5), which is suggestive of the specific function of GSK-3 $\beta$ in $\alpha$ NAC 
a

$\alpha$ NAC

BNAC

p-GSK-3 $\beta$

GSK-3 $\beta$

$\beta$-actin

hypoxia aNAC

Oh 16h 24h $37 \mathrm{~h} 48 \mathrm{~h}$

$\alpha$ NAC

$\begin{array}{lllll}1.0 & 0.8 & 0.6 & 0.3 & 0.2\end{array}$

$\begin{array}{llllll}\text { p-GSK-3 } \beta & 1.0 & 0.7 & 0.6 & 0 & 0\end{array}$

b

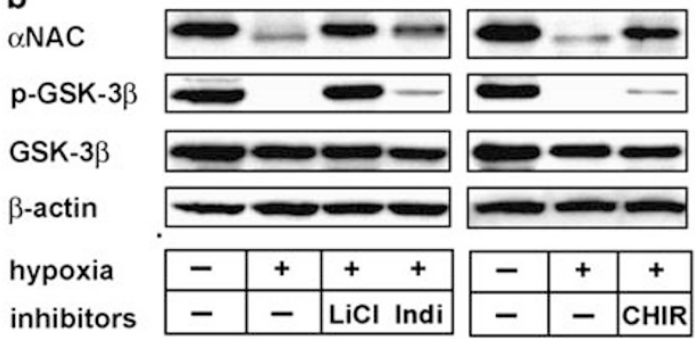

C

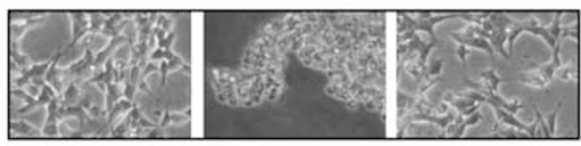

hypoxia

inhibitor

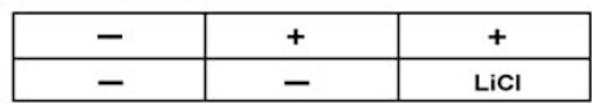

d
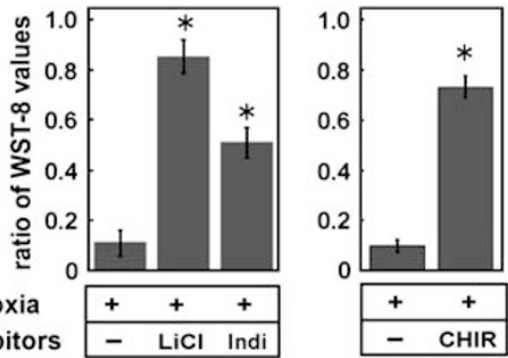

e
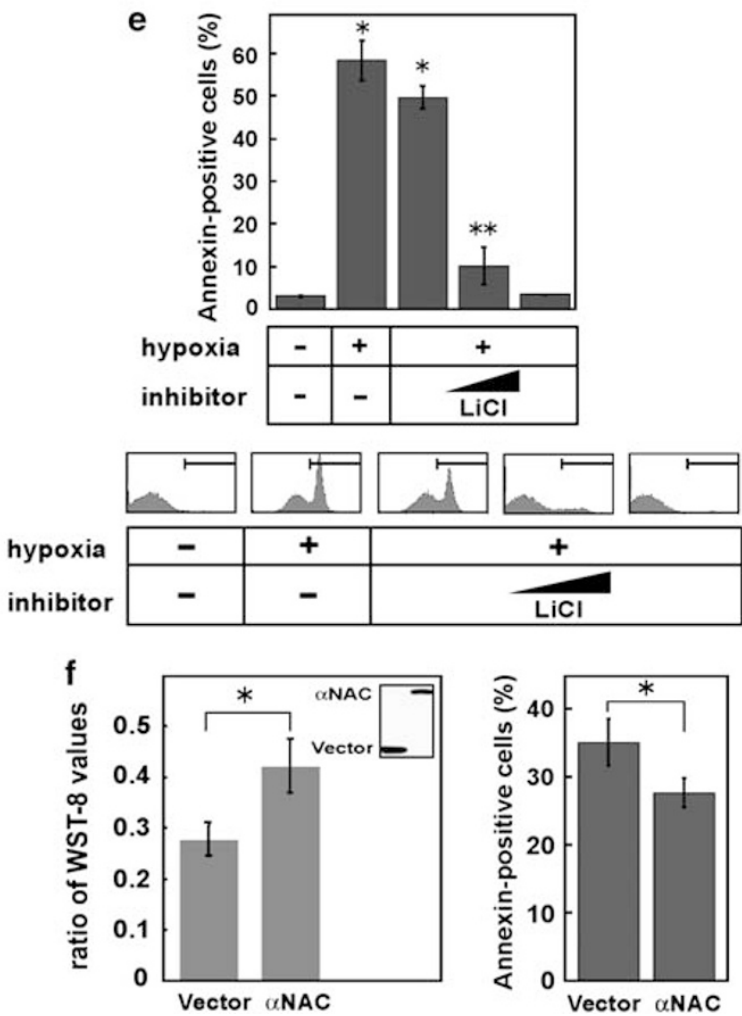

Figure 6 Maintained $\alpha$ NAC protein rescues hypoxic cells from apoptosis. (a) GSK-3 $\beta$ activation in hypoxia. Western blot analysis shows downregulation of phosphorylated (Ser 9) GSK-3 $\beta$ (phospho-GSK-3 $\beta$ ) in hypoxic (0-48 h) SK-N-SH cells. Blots were quantified using a densitometer and $\alpha$ NAC and phosphorylated GSK-3 $\beta$ levels normalized to the corresponding actin levels (bottom). (b) Inhibition of GSK-3 $\beta$ activation by lithium chloride (LiCl, $40 \mathrm{mM}$ ), indirubin (Indi, $10 \mu \mathrm{M}$ ), or CHIR 99021 (CHIR, $10 \mu \mathrm{M}$ ) maintained $\alpha$ NAC protein levels in hypoxic SK-N-SH cells. (c-e) Inhibition of GSK-3 $\beta$ activation rescues hypoxic cells from apoptosis. (c) Phase-contrast micrograph. (d) Lithium chloride, indirubin, or CHIR 99021 increased cell viability of hypoxic SK-N-SH cells. Data are shown as means \pm S.D. $(n=3)$. ${ }^{*}$ Differences are significant $(P<0.01)$ versus hypoxia ( +)/inhibitor (-) cells. (e) Annexin assay shows a dose-dependent (10, 20, and $40 \mathrm{~mm}$ of lithium chloride) suppression of apoptosis in hypoxic SK-N-SH cells. Data are shown as means \pm S.D. $(n=3)$. Differences are significant $\left({ }^{\star} P<0.01,{ }^{\star \star} P<0.05\right)$ versus hypoxia $(-)$ /inhibitor $(-)$ cells. (f) Overexpression of $\alpha$ NAC increased cell viability of hypoxic HeLa S3 cells. Cell viability assay (left panel) and annexin V-binding assay (right panel). Inserted western blotting in left panel indicates protein levels of exogenously introduced full-length $\alpha$ NAC; The whole cell extracts from HeLa S3 cells transfected with pEGFP-N2 vector alone (left lane) or the vector containing $\alpha$ NAC construct (right lane) were analyzed by western blotting using antibodies specific for the EGFP. Data are shown as means \pm S.D. ( $n=6$ for left panel and $n=5$ for right panel). *Difference is significant $(P<0.01)$

degradation and the subsequent apoptotic processes in hypoxic cells.

To support the notion that maintaining the intracellular levels of $\alpha$ NAC can prevent hypoxic cells from apoptosis, we transfected wild-type $\alpha$ NAC into HeLa S3 cells and then cultured the cells under hypoxic conditions. The $\alpha$ NAC transfection exerted mild effects on the viability of hypoxic cells, resulting in a significantly higher cell viability and lower incidence of apoptosis than the cells transfected with the vector alone (Figure 6f). Collectively, these results suggest that $\alpha$ NAC degradation triggers ER stress responses and initiates apoptotic processes in hypoxic cells and that GSK-3 $\beta$ may participate upstream in this mechanism.

\section{Discussion}

In this report, we have presented evidence for the hypoxiainduced GSK-3 $\beta$ activation and the subsequent destabilization of $\alpha$ NAC. $\alpha$ NAC depletion resulted in the activation of ER stress signaling, cytochrome $c$ release from the mitochondria, and caspase-dependent apoptosis. In hypoxic cells, aNAC downregulation occurred before the activation of ER stress 
signaling and the subsequent apoptotic events. More importantly, the prevention of $\alpha$ NAC degradation by GSK-3 $\beta$ inhibition or $\alpha$ NAC overexpression in hypoxic cells rescued the cells from apoptosis.

Several studies have implicated the role of the NAC complex in apoptosis. In particular, Bloss et al. ${ }^{7}$ suggested the protective role of $\beta \mathrm{NAC}$ against cell apoptosis in C. elegans; $\beta \mathrm{NAC}$ inhibits the apoptosis of cells that are normally programed to die. Consistent with this, $\alpha$ NAC in yeasts lacking $\beta \mathrm{NAC}$ rendered the cells heat-sensitive. ${ }^{10}$ $\beta$ NAC downregulation was associated with apoptosis in human cells. ${ }^{34}$ These results suggest that the $\beta$ NAC may function as an antiapoptotic factor. However, the physiological significance of $\alpha \mathrm{NAC}$ in the cell death mechanism has not been well elucidated. This study demonstrates that $\alpha$ NAC downregulation per se can lead to cell apoptosis through the ER stress mechanism in the presence of $\beta$ NAC. A possible but not investigated explanation is that the loss of $\alpha$ NAC might induce the unregulated activities of the other members of the nascent chain-ribosome complexes, including $\beta$ NAC. Beatrix et al. $^{35}$ showed that $\beta \mathrm{NAC}$ alone is sufficient to prevent ribosome binding to the ER. Therefore, $\beta$ NAC may not be a component of the ER-targeted ribosome-nascent chain complexes. However, in the present experiment system, we could not determine whether the deletion of $\alpha \mathrm{NAC}$ alone from the ribosome-nascent chain complexes leads to concomitant dissociation of the $\beta$ NAC subunit from the complex. Further in vitro studies may be required to answer this question.

Apparently, the NAC complexes can bind to nascent polypeptide chains, and the vast majority of $\alpha$ and $\beta$ NAC subunits are involved in the complex formation. ${ }^{35}$ However, there might be individual functions for $\alpha \mathrm{NAC}, \beta \mathrm{NAC}$, and the NAC complex in vivo. ${ }^{36}$ For example, $\beta$ NAC binds to ribosomes, but $\alpha$ NAC does not. ${ }^{10,35}$ Furthermore, mouse $\alpha$ NAC can be active as a transcriptional coactivator, but it loses its activity when $\beta \mathrm{NAC}$ is coexpressed. ${ }^{37}$

Activation of JNK occurs in response to ER stress. ${ }^{20}$ Moreover, an apoptosis signal-regulating kinase (ASK1) is required for TNF receptor-associated factor 2 (TRAF2)dependent JNK activation during TNF-induced apoptosis. ${ }^{21}$ ASK1-deficient cells are resistant to ER stress-induced apoptosis, indicating that the TRAF2/ASK signaling pathway is critical for ER stress-induced apoptosis. ${ }^{38}$ In addition, the interaction between $\alpha \mathrm{NAC}$ and the Fas-associated death domain, which is a critical mediator of the TNF receptormediated signal-transduction pathway, is disrupted in response to TNF. ${ }^{39}$ These results collectively suggest the complementary role of $\alpha \mathrm{NAC}$ degradation in C-Jun-mediated apoptosis. However, JNK activation was not detected in $\alpha$ NAC-depleted cells, suggesting minimal if no contribution of the JNK pathway to the $\alpha$ NAC-dependent apoptosis.

Phosphorylated elF $2 \alpha$ inhibits translation by reducing the formation of translation initiation complex. ${ }^{1}$ It is known that after $24 \mathrm{~h}$ of hypoxia in cell cultures a general shut-down in translation is induced. ${ }^{40}$ Phosphorylated elF $2 \alpha$ also induces apoptosis by activating the ATF4-CHOP pathway. On the other hand, a recent study suggested that $\alpha$ NAC might function as a transcriptional coactivator. ${ }^{37}$ Furthermore, $\alpha$ NAC was reported to interact with $\gamma$-taxilin, which inhibits ATF4-mediated transcription. ${ }^{18,19}$ In this study, we showed that $\alpha$ NAC ablation by the RNA interference resulted in the upregulation of ATF4 and downregulation of $\gamma$-taxilin (Figure 4a), consistent with the previous findings. Therefore, these studies imply that $\alpha \mathrm{NAC}$ and elF2 $\alpha$ might coordinately regulate transcriptional and translational responses of the cell to hypoxia, thereby determining the fate of the hypoxic cell.

Recent studies have suggested that neuronal cell death in $A D$ and ischemia could arise from dysfunction of the ER. ${ }^{16}$ Specific downregulation of $\alpha$ NAC was observed in the brains of patients with $A D$ and Down's syndrome with AD-like neuropathology. ${ }^{5}$ The UPR program is activated to cope with the accumulation of unfolded or misfolded proteins in the ER. ${ }^{1}$ The main role of the UPR is to restore ER function by reducing the load of proteins that are required to be folded and processed in the ER lumen and by increasing the protein folding and processing capacity. ${ }^{16}$ If ER function cannot be restored, cells undergo apoptosis. Therefore, it is plausible that UPR is unable to rescue cells with severe $\alpha$ NAC depletion, as shown in the hypoxic cells and ischemic mouse brains. Along with these results, this notion implies that the aNAC depletion event might occur before ER stress in neuronal cells of ischemic brains.

However, the precise mechanism by which the hypoxic signals trigger the downregulation of $\alpha$ NAC has not been defined. The human $\alpha$ NAC contains a ubiquitin-associated (UBA) domain at its $\mathrm{C}$ terminus, but $\beta$ NAC does not. ${ }^{41}$ In addition, the Saccharomyces cerevisiae NAC complex (EGD), which consists of Egd1p ( $\beta$ NAC) and Egd2p ( $\alpha$ NAC), can be ubiquitinated in vitro through a UBA domain at the $C$ terminus of the Egd2p. ${ }^{42}$ In hypoxic cells, $\alpha$ NAC but not $\beta$ NAC might be degraded through the ubiquitin-protease system (UBS). However, cells undergoing ER stress may exhibit general inhibition of the UBS due to the presence of aberrant ubiquitin. $^{2}$ Therefore, in the later stages of the hypoxic cells and ischemic neurons, the ER stress may further degrade NAC due to impaired UBS activity.

Activation of the phosphatidylinositol-3-kinase (PI3-k)/ protein kinase $B(A K T)$ pathway is associated with hypoxia. ${ }^{43}$ The involvement of GSK-3 $\beta$ has been reported in hypoxia. ${ }^{44}$ In addition, PI3-k/AKT inhibits GSK-3 $\beta$ by phosphorylating at the $\mathrm{N}$ terminus Ser $9 .{ }^{45}$ Therefore, another possible and specific mediator of $\alpha \mathrm{NAC}$ degradation could be GSK-3 $\beta$; $\alpha \mathrm{NAC}$ is a target for degradation by the $26 \mathrm{~S}$ proteasome, which is regulated by GSK3 $\beta$-dependent phosphorylation. ${ }^{28}$ Indeed, this study demonstrated that hypoxic stress was associated with dephosphorylation of GSK-3 $\beta$ and that the inhibition of GSK-3 $\beta$ by lithium ions prevented dephosphorylation of GSK-3 $\beta$ and downregulation of $\alpha$ NAC, which rescued the hypoxic cells from apoptosis (Figure 6). GSK-3 $\beta$ phosphorylates proteins at serine or threonine residues that are located 4 amino acids $\mathrm{N}$-terminal to another phosphoserine (priming phosphorylation), which is introduced by other protein kinases. $^{31}$ The protein kinases that could introduce this priming phosphoserine vary depending on the substrates, and GSK-3 $\beta$ and casein kinase II may be the candidates for $\alpha$ NAC. ${ }^{46}$ However, at present, the $\alpha$ NAC protein does not fulfill all the requirements as a physiological substrate for GSK-3 $\beta{ }^{27,28}$ Further studies are required for determining whether $\alpha$ NAC is a target of GSK-3 $\beta$. Notwithstanding these facts, the phosphorylation-dependent $\alpha$ NAC downregulation 
and the subsequent induction of ER stress are intriguing with regard to understanding the mechanisms for the initiation of ER stress-induced apoptosis in hypoxia.

In this study, we did not find definitive evidence that MAP kinases are involved in the downregulation of $\alpha \mathrm{NAC}$ in hypoxic cells. A previous study has shown that ERK MAP kinase is involved in the ER stress responses of thapsigargin-induced SH-SY5Y cells. ${ }^{33}$ However, the ERK pathway activated by thapsigargin was found to lead to a non-caspase-dependent cell death. Therefore, the detailed upstream regulatory mechanism of $\alpha$ NAC degradation in hypoxia remains to be clarified in future studies.

In conclusion, we have defined the ER stress responses that are initiated by $\alpha$ NAC depletion in mammalian cells. We postulate that this ER stress-response pathway may be involved in the apoptotic mechanism in hypoxic cells.

\begin{abstract}
Materials and Methods
Cell culture and hypoxia treatment. HeLa S3 human cervical cancer cells were cultured in DMEM supplemented with 10\% FBS. SH-SY5Y and SK-N-SH human neuroblastoma cells were both grown in $\alpha$-MEM supplemented with $10 \%$ FBS. The cells were cultured under hypoxic conditions $\left(<1 \% \mathrm{pO}_{2}\right.$ and $\left.5 \% \mathrm{pCO}_{2}\right)$ using an anaerobic culture kit (Mitsubishi Gas Chemicals, Tokyo, Japan). The system provides a hypoxic condition without affecting the $\mathrm{pH}$ of the medium. Z-VADFMK (BD PharMingen, Franklin Lakes, NJ, USA) was used as a pancaspase inhibitor.
\end{abstract}

RNA interference. Oligonucleotides corresponding to human $\alpha$ NAC ( $5^{\prime}$-CCAGUCAGUAAAGCAAAACTT) were transfected 1-3 times at 24-h intervals into HeLa S3 cells using Oligofectamine (Invitrogen, Carlsbad, CA, USA) or Lipofectamine RNAiMax (Invitrogen) according to the manufacturer's instructions. The effect of siRNA was measured 24-96 $\mathrm{h}$ after the first transfection. Luciferase GL2 siRNA (Qiagen) or AllStar Negative Control siRNA (Qiagen, Hilden, Germany) was used as a control.

Immunofluorescence microscopy. Cells were washed with PBS and fixed with $4 \%$ paraformaldehyde in PBS for $20 \mathrm{~min}$, the cells were then permeabilized with $0.2 \%$ Triton X-100 in PBS for $15 \mathrm{~min}$ at room temperature. Blocking was performed with $1.5 \%$ BSA and $1.5 \%$ skim milk in PBS for $1 \mathrm{~h}$ at room temperature. Incubation with the primary antibody was performed overnight at $4^{\circ} \mathrm{C}$. Visualization of the nuclei was achieved by incubating the cells with DAPI $(1 \mu \mathrm{g} / \mathrm{ml})$ for $10 \mathrm{~min}$ at room temperature. Immunofluorescent visualization was carried out under a TCS SP2 AOBS confocal microscope (Leica, Mannheim, Germany).

Cell fractionation and Western blotting. Cells were collected and washed in ice-cold PBS, and fractionated into mitochondrial and cytosolic fractions using a Mitochondria Isolation Kit (PIERCE, Rockford, IL, USA). After centrifugation at $12000 \times g$ for $15 \mathrm{~min}$, the supernatants were pooled as the cytosolic fraction and the pellet for the mitochondrial fraction. The cytosolic fraction was concentrated by trichloroacetic acid precipitation. Equal amounts of proteins were then analyzed on a $15 \%$ polyacrylamide gel.

Antibodies. The antibodies used in this study were as follows: ATF4 (Santa Cruz, Santa Cruz, CA, USA), ATF6 (IMGENEX, San Diego, CA, USA), BIP (KDEL; Stressgen, Ann Arbor, MI, USA), Bcl-2 (Santa Cruz), Bax (Santa Cruz), cytochrome c (BD PharMingen, Danvers, MA, USA), CHOP (GADD 153; Santa Cruz), PERK (Cell Signaling Technology, Danvers, MA, USA), phospho-PERK (Santa Cruz), caspase-4 (Stressgen), cleaved caspase-9 (Cell Signaling Technology), ubiquitin (Cell Signaling Technology or BIOMOL, Plymouth Meeting, PA, USA), elF2 $\alpha$ (Cell Signaling Technology), phospho-elF2 $\alpha$ (Cell Signaling Technology), GSK-3 $\beta$ (Cell Signaling Technology), phospho-GSK-3 $\beta$ (Ser 9) (Cell Signaling Technology), EGFP (Clontech, Mountain View, CA, USA), phospho-JNK (Cell Signaling Technology), $\gamma$-taxilin (Santa Cruz), XBP-1 (Santa Cruz), and $\beta$-actin (Santa Cruz). The antibodies against $\alpha$ NAC and $\beta$ NAC were described previously. ${ }^{4}$
GSK-3 $\beta$, ERK, and p38 MAPK inhibition and $\alpha$ NAC transfection. Lithium chloride (Sigma, St Louis, MO, USA), CHIR 99021 (STEMGENT, Cambridge, MA, USA), and 5-iodo-indirubin-3'-monoxime (Calbiochem, San Diego, CA, USA) were used as pharmacological inhibitors of GSK-3 $\beta$. U0126 (Calbiochem) and SB 202190 (Calbiochem) were used for the inhibition of ERK and p38 MAPK, respectively. HeLa S3 cells were transfected with pEGFP-N2 vector (Clontech) containing the full-length $\alpha$ NAC using Effecten Transfection Reagent (Qiagen).

Assessment of apoptosis and cell viability. The TUNEL assay was performed using an in situ Cell Death Detection Kit TMR Red (Roche, Basel, Schweiz, Switzerland) according to the manufacturer's protocol. Apoptosis was also assessed after incubating cells with Annexin V-FITC (Sigma), or Annexin V-Cy3 (Sigma) at room temperature for $10 \mathrm{~min}$. Cells positive for TUNEL or Annexin were analyzed by FACS scan. Cell viability was measured by a modified MTT dye reduction assay using WST-8 (2-(2-methoxy-4-nitrophenyl)-3-(4-nitrophenyl)-5(2,4-disulfophenyl)-2H-tetrazolium, monosodium salt) (Dojindo Molecular Technologies, Kumamoto, Japan). Fraction viable cells represent the ratio of WST-8 values obtained from treated cells relative to untreated cells.

Mouse stroke model and immunohostochemistry. The experiments using mice were performed following an institutionally approved protocol in accordance with the National Institute of Health Guide for the Care and Use of Laboratory Animals. A standard intraluminal middle cerebral artery method using a 7.0 nylon, silicon-coated monofilament was used to establish a mouse model for focal cerebral ischemia/reperfusion. ${ }^{14}$ After a 2-h occlusion, the filament was withdrawn to reperfuse the ischemic brain. Laser Doppler flowmetry was used to monitor cerebral cortical microperfusion to confirm the adequate induction of focal ischemia and successful reperfusion. Blood gases and blood pressure were measured before the induction of ischemia and also in ischemic mice after a 2-h occlusion of the middle cerebral artery. The ischemic brains were examined $22 \mathrm{~h}$ after the reperfusion. The brains were excised after transcardial perfusion with icecold phosphate-buffered $4 \%$ paraformaldehyde in PBS (pH 7.4). The frozen sections (20 mm thick) were blocked and permeabilized in PBS containing $0.2 \%$ Triton-X and $3 \%$ normal goat serum, and then incubated overnight at $4{ }^{\circ} \mathrm{C}$ in the presence of appropriately diluted antibodies. The ischemic and contralateral hemispheres were separately homogenized in cell lysis buffer (Cell Signaling Technology) and subjected to western blotting.

1. Lie CY, Kaufman RJ. The unfolded protein response. J Cell Sci 2003; 116: 1861-1862.

2. Menéndez-Benito V, Verhoef LGGC, Masucci MG, Dantuma NP. Endoplasmic reticulum stress comprises the ubiquitin-proteasome system. Hum Mol Genet 2005; 14: 2787-2799.

3. Fünfschilling U, Rospert $S$. Nascent polypeptide-associated complex stimulates protein import into yeast mitochondria. Mol Biol Cell 1999; 10: 3289-3299.

4. Wiedmann B, Sakai H, Davis TA, Wiedmann M. A protein complex required for signalsequence-specific sorting and translocation. Nature 1994; 370: 434-440.

5. Kim SH, Shim KS, Lubec G. Human brain nascent polypeptide-associated complex a subunit is decreased in patients with Alzheimer's disease and Down syndrome. J Investing Med 2002; 50: 293-301.

6. Kroes RA, Jastrow A, McLone MG, Yamamoto H, Colley P, Kersey DS et al. The identification of novel therapeutic targets for the treatment of malignant brain tumors. Cancer Lett 2000; 156: 191-198.

7. Bloss TA, Witze ES, Rothman JH. Suppression of CED-3-independent apoptosis by mitochondrial $\beta$ NAC in Caenorhabditis elegans. Nature 2003; 424: 1066-1071.

8. Den JM, Behringer RR. An insertion in the BTF3 transcription factor gene leads to an early postimplantation lethality in mice. Transgenic Res 1995; 4: 264-269.

9. Markesic DC, Gajewski KM, Nazimiec ME, Beckingham K. Beicaudal encodes the Drosophila beta NAC homolog, a component of the ribosomal translational machinery. Development 2000; 127: 559-572.

10. Reimann B, Bradsher J, Franke J, Hartmann E, Wiedmann M, Prehn S et al. Initial characterization of the nascent polypeptide-associated complex in yeast. Yeast 1999; 15: 397-407.

11. Kaufman RJ, Scheuner D, Schröder M, Shen X, Lee K, Lie CY et al. The unfolded protein response in nutrient sensing and differentiation. Nat Rev Mol Cell Biol 2002; 3: 411-421.

12. Brown JM, Wilson WR. Exploiting tumor hypoxia in cancer treatment. Nat Rev Cancer 2004; 4: 437-447.

13. Yang MH, Wu MZ, Chou SH, Chen PM, Chang SY, Liu CJ et al. Direct regulation of TWIST by HIF-1 $\alpha$ promotes metastasis. Nat Cell Biol 2008; 10: 295-305.

14. van Leyen K, Kim HY, Lee SR, Jin G, Arai K, Lo EH. Baicalein and 12.15-lipoxygenase in the ischemic brain. Stroke 2006; 37: 3014-3018.

15. Paschen W. Endoplasmic reticulum: a primary target in various acute disorders and degenerative diseases of the brain. Cell Calcium 2003; 34: 365-383. 
16. Paschen W, Mengesdorf T. Endoplasmic reticulum stress response and neurodegeneration. Cell Calcium 2005; 38: 409-415.

17. Rutkowski DT, Kaufman RJ. A trip to the ER: coping with stress. Trends Cell Bio/ 2004; 14: 20-28.

18. Yu VWC, Ambartsoumian G, Verlinder L, Moir JM, Pru'homme J, Gauthier $C$ et al. FIAT represses ATF4-mediated transcription to regulate bone mass in transgenic mice. $J$ Cell Biol 2005; 169: 591-601.

19. Yoshida K, Nogami S, Satoh S, Tanaka-Nakadate S, Hiraishi H, Terano A et al. Interaction of the taxilin family with the nascent polypeptide-associated complex that is involved in the transcriptional and translational processes. Genes to Cells 2005; 10: 465-476.

20. Urano F, Wang XZ, Bertolotti A, Zhang Y, Chung P, Harding PHP et al. Coupling of stress in the ER to activation of JNK protein kinases by transmembrane protein kinase IRE1. Science 2000; 287: 664-666.

21. Nishitoh H, Matsuzawa A, Tobiume K, Saegusa K, Takeda K, Inoue K et al. ASK1 is essential for endoplasmic reticulum stress-induced neuronal cell death triggered by expanded polyglutamine repeats. Genes Dev 2002; 16: 1345-1355.

22. Yoshida H, Matsui T, Yamamoto A, Okada T, Mori K. XBP1 mRNA is induced by ATF6 and spliced by IRE in response to ER stress to produce a highly active transcription factor. Cell 2001; 107: 881-891.

23. Ding WX, Ni HM, Gao W, Yoshimori T, Stolz DB, Ron D et al. Linking of autophagy to ubiquitin-proteasome system is important for the regulation of endoplasmic reticulum stress and cell viability. Am J Pathol 2007; 171: 513-524

24. Egger L, Madden DT, Rhême C, Rao RV, Bredesen DE. Endoplasmic reticulum stressinduced cell death mediated by the proteasome. Cell Death Differ 2007; 14: 1172-1180.

25. Rao R, Ellerby HM, Bredesen DE. Coupling endoplasmic reticulum stress to the cell death program. Cell Death Differ 2004; 11: 372-380.

26. Obeng EA, Boise LH. Caspase- 12 and caspase- 4 are not required for caspase-dependent endoplasmic reticulum stress-induced apoptosis. J Biol Chem 2005; 280: 29578-29587.

27. Cohen P, Frame S. The renaissance of GSK3. Nat Rev Mol Cell Biol 2001: 2: 769-776.

28. Quélo I, Akhouayri O, Prud'homme J, St-Arnaud R. GSK3 $\beta$-dependent phosphorylation of the NAC coactivator regulates its nuclear translocation and proteasome-mediated degradation. Biochemstry 2004; 43: 2906-2914.

29. Klein PS, Melton DA. A molecular mechanism for the effect of lithium on development. Proc Natl Acad Sci USA 1996; 93: 8455-8459.

30. Jope RS. Lithium and GSK-3: one inhibitor, two inhibitory actions, multiple outcomes. Trends Pharmacol Sci 2003; 24: 441-443.

31. Cohen P, Goedert M. GSK3 inhibitors: development and therapeutic potential. Nat Rev Drug Discov 2004; 3: 479-487.

32. Thornton TM, Pedraza-Alva G, Deng B, Wood CD, Aronshtam A, Clements TL et al. Phosphorylation by $\mathrm{p} 38$ MAPK as an alternative pathway for GSK3 $\beta$ inactivation. Science 2008; 320: 667-670.
33. Arai $\mathrm{K}$, Lee SR, van Leyen $\mathrm{K}$, Kurose $\mathrm{H}$, Lo EH. Involvement of ERK MAP kinase in endoplasmic reticulum stress in SH-SY5Y human neuroblastoma cells. J Neurochemistry 2004; 89: 232-239.

34. Thiede B, Dimmler C, Siejak F, Rude T. Predominant identification of RNA-binding proteins in Fas-induced apoptosis by proteome analysis. J Biol Chem 2001; 276: 26044-26050.

35. Beatrix B, Sakai $\mathrm{H}$, Wiedmann $\mathrm{M}$. The $\alpha$ AND $\beta$ subunit of the nascent polypeptide-associated complex have distinct functions. J Biol Chem 2000; 275 37838-37845.

36. Rospert S, Dubaquié Y, Gautschi M. Nascent-polypeptide-associated complex. CMLS Cell Mol Life Sci 2002; 59: 1632-1639.

37. Yotov WV, Moreau A, St-Arnaud R. The alpha chain of the nascent polypeptideasssociated complex functions as a transcriptional coactivator. Mol Cell Biol 1998; 18 1303-1311.

38. Kadowaki $\mathrm{H}$, Nishitoh $\mathrm{H}$, Urano F, Sadamitsu C, Matsuzawa A, Takeda K et al. Amyloid $\beta$ induces neuronal cell death through ROS-mediated ASK1 activation. Cell Death Diff 2005; 12: $19-24$.

39. Stilo R, Liguoro D, di Jeso B, Leonardi A, Vito P. The alpha-chain of the nascent polypeptide-associated complex binds to and regulates FADD function. Biochem Biophys Res Commun 2003; 303: 1034-1041.

40. Thomas JD, Johannes GJ. Identification of mRNA that continue to associate with polysomes during hypoxia. RNA 2007; 13: 1116-1131.

41. Spreter T, Pech M, Beatrix B. The crystal structure of archaeal nascent polypeptideassociated complex (NAC) reveals a unique fold and the presence of a ubiquitin-associated domain. J Biol Chem 2005; 280: 15849-15854.

42. Panasenko O, Landrieux E, Feuermann M, Finka A, Paquet N, Collart MA. The yeast Ccr4Not complex controls ubiquitination of the nascent-associated polypeptide (NAC-EDG) complex. J Biol Chem 2006; 281: 31389-31398.

43. Bussink J, van der Kogel AJ, Kaanders JHAM. Activation of the PI3-K/AKT pathway and implications for radioresistance mechanisms in head and neck cancer. Lancet Oncol 2008 9: 288-296.

44. Loberg RD, Vesely E, Brosius III FC. Enhanced glycogen synthase kinase- $3 \beta$ activity mediates hypoxia-induced apoptosis of vascular smooth muscle cells and is prevented by glucose transport and metabolism. J Biol Chem 2002; 277: 41667-41673.

45. Cross DAE, Alessi DR, Cohen $P$, Andjelkovich M, Hemmings BA. Inhibition of glycogen synthase kinase-3 by insulin mediated by protein kinase B. Nature 1995; 378: 785-789.

46. Quélo I, Gauthier C, St-Arnaud R. Casein kinase II phosphorylation regulates alphaNAC sucellular localization and transcriptional coactivating activity. Gene Expr 2005; 12: 151-163

\section{Supplementary Information accompanies the paper on Cell Death and Differentiation website (http://www.nature.com/cdd)}

